\title{
The influence of expatriate cultural intelligence on organizational embeddedness and knowledge sharing: The moderating effects of host country context
}

\author{
Sebastian Stoermer ${ }^{1}$, \\ Samuel Davies ${ }^{2}$ (1) and \\ Fabian Jintae Froese ${ }^{3,4}$
}

\footnotetext{
${ }^{1}$ Junior Professorship in Human Resources Management, Technical University of Dresden, Schumann-Bau, B-Wing, Office 232, 01187 Dresden, Germany; ${ }^{2}$ University of Liverpool Management School, University of Liverpool, Chatham Street, Liverpool L69 7ZH, UK; ${ }^{3}$ Chair of Human Resources Management and Asian Business, University of Goettingen, Platz der Goettinger Sieben 5, 37085 Goettingen, Germany; ${ }^{4}$ School of Business, Yonsei University, 50 Yonsei-ro, Seodaemun-gu, Seoul 03722, Republic of Korea
}

\section{Correspondence:}

FJ Froese, Chair of Human Resources Management and Asian Business, University of Goettingen, Platz der Goettinger Sieben 5, 37085 Goettingen, Germany e-mail: fabian.froese@gmail.com

\begin{abstract}
This study advances our understanding of the contextualization of the effects of cultural intelligence (CQ). Drawing from trait activation theory and institutional theory, we develop a multi-level model showing how host countries' informal and formal openness towards foreigners facilitate or constrain the importance of expatriates' CQ in becoming embedded in the host organization. Furthermore, this study positions organizational embeddedness as a mediator in the association between expatriates' CQ and a central element of expatriates' jobs - knowledge sharing in the foreign workplace. Results from a cross-lagged survey of 1327 expatriates from 100 different nations residing in 30 host countries combined with secondary data indicate expatriate $C Q$ relates positively to organizational embeddedness. Cross-level interaction analyses further suggest that in-group collectivism, the proxy for host countries' informal openness towards foreigners, facilitates the importance of $C Q$ as a predictor of expatriates' organizational embeddedness. In contrast, CQ was not found to interact with the proxy for host countries' formal openness towards foreigners, i.e. national immigration policies. Consistent with predictions, we identified that $\mathrm{CQ}$ relates positively to knowledge sharing and that organizational embeddedness carries an indirect effect. We discuss the implications for theory and practice.
\end{abstract}

Journal of International Business Studies (2021) 52, 432-453.

https://doi.org/ | 0. 1057/s4 I 267-020-00349-3

Keywords: expatriate management; cultural intelligence; in-group collectivism; immigration policies; organizational embeddedness; knowledge sharing; trait activation theory; multi-level analysis

The online version of this article is available Open Access

\section{INTRODUCTION}

An essential element of the expatriation experience is the relationship between the expatriate and the host country environment (Ren, Shaffer, Harrison, Fu, \& Fodchuck, 2014). To become immersed into the new environment, expatriates need to navigate
Received: 15 August 2018

Revised: 16 January 2020

Accepted: 9 May 2020

Online publication date: 20 August 2020 
a number of challenges including making sense of and understanding the foreign environment (Farh, Bartol, Shapiro, \& Shin, 2010; Sanchez, Spector, \& Cooper, 2000; Shaffer \& Miller, 2008). In this respect, early anthropological work on expatriates compared the exposure to an unfamiliar culture with fish having been taken out of the water (Oberg, 1960). Based on the increasing utilization of international assignees in multinational enterprises (MNEs) and a heightened permeability of domestic job markets for skilled foreign labor, research in cross-cultural management has paid major attention to the factors that help expatriates find their place in the foreign environment (see for a meta-analysis: Bhaskar-Shrinivas, Harrison, Shaffer, \& Luk, 2005). One critical factor that emerged over the last two decades is cultural intelligence (CQ) (Earley, 2002; Earley \& Ang, 2003; Thomas, 2006; Thomas et al., 2008, 2015). Defined as "the ability that individuals have to interact effectively across cultural contexts and with culturally different individuals" (Thomas et al., 2015: 1100), CQ has been theorized to enable understanding, adaptation and shaping of the cross-cultural context individuals operate in (Thomas, 2006; Thomas et al., 2008, 2015). While research on CQ has burgeoned since its inception (Ang, Van Dyne, \& Koh, 2006; Ang et al., 2007; Chen, Kirkman, Kim, Farh, \& Tangirala, 2010; Firth, Chen, Kirkman, \& Kim, 2014; Froese, Kim, \& Eng, 2016; Guang \& Charoensukmongkol, 2020; Ott \& Michailova, 2018), several pressing questions remain. This disarray primarily revolves around the effectiveness of CQ across differing country contexts (Ott \& Michailova, 2018) and an overwhelming focus on CQ as a driver of (reactive) adjustment instead of proactive crafting of and embedment into the foreign environment. Ultimately, we know little about how and when expatriates can use CQ to their benefit to embed in organizations.

To provide answers to these vital questions, the present study develops a multi-level model of how CQ enables expatriates' embeddedness in the host organization and how the relevance of CQ in doing so differs depending on the characteristics of the host country environment. Organizational embeddedness captures individuals' perceptions of how strongly they are enmeshed in the host organization (Lee, Mitchell, Sablynski, Burton, \& Holtom, 2004; Mitchell, Holtom, Lee, Sablynski, \& Erez, 2001) and is the outcome of expatriates' proactive actions to adjust, shape and craft their environment (Ren et al., 2014). It thus, differs from cross- cultural adjustment, which reflects more of a reaction to the stressors associated with living abroad (Ren et al., 2014). Following this line of thought, our study shifts the predominant perspective from expatriates being confined to merely reacting to their environment (e.g., Bhaskar-Shrinivas et al., 2005; Black, Mendenhall, \& Oddou, 1991; Zhang, 2013), to positioning expatriates as proactive agents that are not only able to adapt but also to exert influence on their situation in the host organization.

Further, while we build our model around the idea that CQ is in general an invaluable quality to establish embeddedness, we contextualize CQ and integrate host country moderators that likely facilitate or constrain the importance of CQ. This is in line with recent calls emphasizing that contextualization of CQ is warranted (Ott \& Michailova, 2018) and presents an essential piece to understanding variations in CQ's effectiveness across contexts. Given that embeddedness represents immersion and integration into the host country organization, we consider host country openness towards foreigners as a boundary condition that increases or decreases the relevance of culturally intelligent behaviors in becoming embedded. In accordance with the classification of country environments into informal and formal elements in institutional theory (North, 1990), we distinguish between ingroup collectivism (House, Hanges, Javidan, Dorfman, \& Gupta, 2004) as a proxy for host countries openness towards foreigners on the informal level and immigration policies as a manifestation of openness on the formal level (Chen \& Shaffer, 2017). Building upon this fine-grained taxonomy of host country environments, we introduce the situational facilitator/constraint concept from trait activation theory (TAT) (Tett \& Guterman, 2000; Tett \& Burnett, 2003; Tett, Simonet, \& Brown, 2013). According to the theory, traits and abilities (Tett \& Burnett, 2003; Tett et al., 2013), such as CQ, will be more or less likely activated and expressed depending on situational cues conveying the relevance of a certain trait or ability. Hence, we propose that CQ might be more relevant and its effects on organizational embeddedness become facilitated if expatriates deal with little openness towards foreigners on the informal, cultural level as reflected in in-group collectivism; and constrained if reclusiveness takes a different Gestalt in the shape of socio-political, legislative restrictions. Adopting this lens on the subtle moderating role of the host country environment advances existing knowledge 
on the boundary conditions of CQ, which have mainly focused on (subsidiary) cultural distance as a moderator (Chen et al., 2010; Kim, Kirkman, \& Chen, 2008; Zhang, 2013).

In addition, our study seeks to promote our understanding of the relationship between CQ and a highly important, yet neglected variable in expatriation research: knowledge sharing. A key role of expatriates, be it assigned (AEs) or self-initiated expatriates (SIEs), is the sharing of knowledge in the foreign workplace (Chang, Gong, \& Peng, 2012; Harzing, 2001; Harzing, Pudelko, \& Reiche, 2016; Heizmann, Fee, \& Gray, 2018; Wang, Tong, Chen, $\&$ Kim, 2009). However, despite the significance of knowledge sharing, the role of CQ as a potential facilitator continues to be unexplored and we know little of the drivers of knowledge sharing in the expatriation context. As compared to mono-cultural contexts, there are additional impediments to knowledge sharing in a cross-cultural working environment - for instance, divergent ways of communicating and dissimilar mental logics (e.g., Bruning, Sonpar, \& Wang, 2012; Nisbett, 2003; Peltokorpi, 2006). In our model, we theorize that CQ can bridge these cross-cultural divides and enable knowledge sharing directly and, further, indirectly via allowing expatriates to embed more deeply in their organization.

We test our conceptual model with a multi-level data set. We collected cross-lagged data from 1327 expatriates from 100 different home countries. These expatriates are spread across 30 different host locations that have been carefully selected to represent the ten cultural clusters of the GLOBEstudy (House et al., 2004). We combine individuallevel cross-lagged data with secondary data from the GLOBE-study and data from the United Nations on international migration policies (United Nations, 2013a) to elucidate the effects of CQ on embeddedness, knowledge sharing, and, most importantly, the interplay between CQ and the host country environments. To our best knowledge, such a large-scale research endeavor is unprecedented in academic research on expatriates.

This study makes a major contribution to the literatures on CQ and expatriates by providing novel insights into the contextualization of CQ and by shifting the focus on CQ as an ability that allows expatriates to proactively embed into the host organization and to engage in knowledge sharing. Above and beyond this, our study consolidates the recent elaborations regarding abilities within TAT and demonstrates the utility of the refined TAT- framework. We also expand TAT by adding another layer of investigation to the theory - the country level. We, thus, contribute to harnessing the explanatory power of the theory. The study also makes a contribution to research on embeddedness by extending its nomological network and illuminating CQ as an individual level antecedent and its country level boundary conditions in an international work context. Finally, from our findings, we can derive important implications for practitioners in human resource management (HRM) and global mobility departments.

\section{LITERATURE REVIEW}

\section{History and Current Stance of CQ Research}

The initial conceptualization of CQ was developed by Earley (2002) and Earley and Ang (2003). The authors defined CQ as a multifaceted construct consisting of three dimensions, i.e. cognition (including meta-cognition), behavior, and motivation. Following their model, cognition captures individuals' knowledge about other cultures; behavior mirrors individuals' ability to perform culturally competent behavior; and motivation reflects individuals' willingness to enact such behavior. Later, Ang et al. $(2006,2007)$ developed and validated a four-dimensional scale of CQ, positioning metacognition as a stand-alone facet. While valuable and groundbreaking in their approach to understanding how individuals operate within crosscultural environments, this conceptualization of CQ has drawn some criticism in recent research, e.g., regarding discriminant validity problems particularly, a high correlation with emotional intelligence; unspecified relationships between single facets of CQ; an often disintegrated examination of single CQ facets and outcome relationships (e.g., Bücker, Furrer, \& Lin, 2015; Ott \& Michailova, 2018; Ward, Fischer, Zaid Lam, \& Hall, 2008).

Thomas (2006) and Thomas et al. (2008, 2015) developed a somewhat related, yet distinct conceptualization of CQ. Unlike Ang et al.'s (2006, 2007) four-factor model, Thomas et al.'s approach consists of three dimensions. The first is cultural knowledge which captures individuals' awareness of how cultures differ and how cultures influence behavior. The second dimension is labeled crosscultural skills and refers to individuals' ability to modify behaviors appropriately to the respective cultural context, including skills such as perceptual acuity and empathy in cross-cultural interactions. 
The third dimension is specified as meta-cognition, which reflects individuals' awareness and control of their own thinking, behavior, and learning in situations encompassing cross-cultural interactions (Thomas et al., 2008, 2015). Departing from Earley and Ang's (2003) and Ang et al.'s (2006, 2007) approach, Thomas et al. (2008) highlight the pivotal role of meta-cognition for enacting culturally intelligent behavior and for accomplishing goals in cross-cultural interactions. Thomas et al., therefore, argue that culturally intelligent behavior is not the outcome of individuals' motivation, but rather, of a meta-cognitive regulatory mechanism. In accordance with this conceptualization, Thomas et al. $(2008,2015)$ operationalize CQ as a secondorder construct. One of the most crucial differences between Thomas et al.'s and Earley and Ang's approach to CQ is that Thomas et al. theorize CQ's facets to be interactive; while Earley and Ang propose individually operating sub-dimensions. Thus, Thomas et al. (2008) consider CQ's facets to interact within a system, with meta-cognition as the pivotal linking function. This linking function of meta-cognition forms culturally intelligent behaviors by acting as a binding, developmental medium within which cultural knowledge and cultural skills can operate and change in their external expressions as culturally intelligent behaviors. Thomas et al. (2008) use a metaphor of metacognition as a soup broth, and cultural knowledge and skills as the ingredients that go into that broth. This meta-cognitive binding agent is conceptualized as the most dynamic element of CQ, which can be developed over time (e.g. through more intercultural interactions), to further enrich the application of cultural knowledge and skills. In our view, this detailed explication of the internal operation of CQ that leads to culturally intelligent behaviors allows for more specific explanations of hypothesized relationships between CQ and respective outcomes of interest. The conceptual clarity of CQ's interactive internal operation and the theorization of CQ as a single second-order construct are, thus, the primary reasons we adopt Thomas et al.'s $(2008,2015)$ approach to CQ in this study.

In terms of its application, CQ's origins were partly derived from international experience and cultural exposure (Earley \& Ang, 2003, Ott \& Michailova, 2018). Earley (2002) initially positioned CQ as an ability useful for multicultural teams and international assignments. In 2007, Ang et al. published the 20-item CQS-inventory and provided initial evidence that CQ-facets, for instance, behavioral CQ, were positively related to variables such as interaction adjustment and work adjustment. Logically, in subsequent years, CQ gathered increased attention from expatriate management scholars with the construct being positioned as a crucial individual difference that helps to understand how expatriates negotiate crosscultural divides. In this respect, Lee and Sukoco (2010) examined the effects of overall CQ on expatriates' acculturation and performance outcomes. Their study empirically corroborated that CQ relates positively to cross-cultural adjustment and that cross-cultural adjustment and cross-cultural effectiveness mediate the effects of CQ on expatriate performance. Similar findings pertaining to the favorable effects of overall CQ on crosscultural adjustment were obtained in the study by Guðmundsdóttir (2015) who examined expatriates from Northern Europe in the United States. Furthermore, Elenkov and Manev (2009) in a survey of senior expatriate leaders and subordinates demonstrated that overall CQ facilitated the positive relationship between visionary-transformational leadership and organizational innovation. With regard to the interplay between CQ and contextual boundary conditions, the to-date most seminal work has been conducted by Chen et al. (2010). The authors focused on the motivational facet of Ang et al.'s (2007) CQ conceptualization and investigated subsidiary cultural distance as a moderator of the relationship between expatriates' motivational CQ and work adjustment. Interestingly, and in contrast to prior theorizations (Kim et al., 2008), their result suggested that the relationship between motivational CQ and work adjustment was weaker in subsidiaries characterized by high levels of cultural distance.

In terms of knowledge outcomes, there has been little pertinent research on the relationship between CQ and knowledge sharing in expatriate research or related fields. One exception is the study of Chen and Lin (2013) who found a positive relationship of CQ (except behavioral CQ) with knowledge sharing activities in multicultural teams. In particular, meta-cognitive CQ stood out as a strong antecedent of knowledge sharing. Having provided a review of the CQ literatures, we next proceed with developing our conceptual model and hypotheses. 


\section{HYPOTHESES DEVELOPMENT}

\section{$\mathrm{CQ}$ and Organizational Embeddedness}

The organizational (on-the-job) domain of embeddedness is theorized to consist of three facets: Fit refers to the compatibility and comfort individuals perceive with their organization and the organizational environment; links relates to the relationships individuals have with other organizational members; and sacrifice captures individuals' perceptions of the perks associated with working for their organization (Mitchell et al., 2001). Research on embeddedness often alludes to embedded individuals as immersed figures that can hardly be distinguished from their environment (Lee, Burch, \& Mitchell, 2014; Mitchell et al., 2001). In contrast to a domestic setting, there are several particularities of working in a foreign environment that complicate expatriates' immersion into the host organization and that make them feel they stand out. Pertinent research in this respect, for instance, highlighted that expatriates will have problems in social interactions with host country nationals (HCN) in work as their extant knowledge of social encounters is not readily transferable to the host country (Fu \& Shaffer, 2008; Toh \& DeNisi, 2007). Similarly, values between expatriates and local colleagues can differ, which compromises efficient interactions (Van Vianen, De Pater, Kristof-Brown, $\&$ Johnson, 2004). Further, expatriates have been shown to become disillusioned with their working situation abroad due to an experienced incongruence between their qualities and the requirements and opportunities their environment has to offer (Bolino \& Feldman, 2000; Lee, 2005). As such, their abilities and career goals fit poorly into the host country work environment. Also, categorizing, processing and understanding of environmental cues differ from the home environment (Oddou \& Mendenhall, 1984). This increases expatriates' susceptibility to the uncertainties of the host work environment (Ren et al., 2014) and leads to disengagement with the environment and, thus, little appreciation of the job in the host country.

Drawing from TAT (Tett \& Burnett, 2003; Tett et al., 2013), we propose that high CQ expatriates will embed more easily and that CQ prevents several of the aforementioned barriers to embeddedness before they emerge. TAT describes the activation of traits and abilities through situational cues that convey the relevance and utility of a respective trait/ability (Tett et al., 2013). Most often these cues are related to the demands of the working situation (Tett \& Burnett, 2003). The cross-cultural element of the expatriation experience, for instance, when working with $\mathrm{HCN}$, is an omnipresent and highly salient situational demand on expatriates. Thus, CQ as the ability to make sense of the foreign environment and to effectively act in this environment should have high situational relevance leading to its activation and expression (Tett et al., 2013). According to the conceptualization of CQ by Thomas et al. $(2008,2015)$, this activation should take place via its meta-cognition component. Meta-cognition represents the awareness of cultural influences on the specifics and requirements of the situation and is in charge of focusing cognitive resources to create effective behaviors. High CQ individuals have been argued to know how to behave in accordance with the behavioral expectations, values, norms, and internal logics of another culture (Thomas, 2006). This will protect high CQ expatriates from affronting local colleagues and provide greater comfort in interactions for both themselves and locals. This should strengthen ties and involvement and also encourage expatriates to proactively build links with HCN-colleagues. Further, by means of anticipation based on declarative knowledge of the host country, high CQ expatriates can map themselves into the foreign environment (Thomas et al., $2008,2015)$. This allows them to develop realistic previews of their working reality in the host country and, hence, counteracts poor fit before it can occur. CQ can further be used to establish fit with the environment by proactively crafting it. For instance, expatriates can initiate negotiations with their organization/supervisors. Negotiation styles differ across cultures and CQ has been shown to contribute to effectiveness in cross-cultural negotiations (Imai \& Gelfand, 2010). The underlying causes of this effectiveness are that high CQ individuals apply more integrative negotiation tactics and invest more cognitive effort into understanding their cross-cultural negotiation partner (Imai \& Gelfand, 2010). Thus, we propose that high CQ expatriates will have the sure instinct and diplomacy necessary to advocate their self-interest while simultaneously considering the viewpoints of their negotiation counterparts. Similarly, we believe that feeling confident and successful in cross-cultural interactions will increase expatriates' perceptions of the opportunities situated in their organizational environment - for instance, in terms of climbing ranks, making a career, and improving 
salary. Therefore, being culturally intelligent will support expatriates' in proactively exploiting the opportunities of the host organizational environment. Given the outlined benefits of $\mathrm{CQ}$, we postulate:

Hypothesis 1: Expatriate CQ relates positively to organizational embeddedness.

\section{The Moderating Effects of Host Country Context} International management/business research has established that country context has an important influence on individual attitudes and behaviors (e.g., Kirkman, Lowe, \& Gibson, 2006; Rockstuhl et al., 2020). One stream of this research focuses on context as a moderator of phenomena on the individual level (e.g., Peltokorpi \& Froese, 2014; Smale et al., 2019). In respect to CQ, host country context has been frequently positioned as a potentially relevant boundary condition (Chen et al., 2010; Kim et al., 2008; Ott \& Michailova, 2018), suggesting that CQ might be more or less important depending on the particularities of the environment. For the relationship between CQ and organizational embeddedness, we consider host country openness towards foreigners as a germane moderator (e.g., Chen \& Shaffer, 2017). Following institutional theory (North, 1990), we partition the country environment into informal and formal elements. The informal environment relates to culture, which "refers to the shared meanings, motives, beliefs, and interpretations of events that members of a collective carry (House et al., 2004: 15)." The formal environment is in contrast defined as laws, policies, and constitutions (North, 1990; Peng, Wang, \& Jiang, 2008). Both formal and informal environments are related to each other and culture has been considered as the foundations or underpinnings of formal institutions and their configurations (Redding, 2005). Therefore, formal institutions can be understood as tangible and codified manifestations of culture (Holmes, Miller, Hitt, \& Salmador, 2013), and while being interrelated, informal and formal institutions take a different Gestalt and are made of different "material" properties. Drawing from the related, extant expatriate literature, we focus on in-group collectivism (Varma, Toh, \& Budhwar, 2006) as a proxy for host countries' openness on the informal level and immigration policies (Chen \& Shaffer, 2017) as a proxy on the formal level. Next, we develop specific hypotheses for each proxy.

\section{In-group collectivism}

The GLOBE-study proposes that cultures can be differentiated along nine distinct cultural value dimensions (House et al., 2004). When it comes to CQ as an enabler of expatriates' immersion into the host organization, we believe that the in-group collectivism dimension is a particularly important boundary condition that increases/decreases the consequences of culturally intelligent behaviors. The dimension mirrors the degree to which individuals show loyalty, pride and cohesiveness to members of their in-group (House et al., 2004). Being "ex patria", nationality is a highly salient characteristic that distinguishes expatriates from local colleagues and often serves as a point of reference for classifying expatriates as out-group members (Toh \& DeNisi, 2007; Sonesh \& DeNisi, 2016; Varma et al., 2006). Individuals engage in these behaviors to maximize intragroup identification and intergroup differentiation (Oakes, Turner, \& Haslam, 1991). Similarly, expatriates' attitudes, values and behaviors might not be in line with the expectations of the locals. Notably, such deviance is not well regarded in collectivist countries (Bader, Froese, Achteresch, \& Behrens, 2017) and should further perpetuate expatriates' salient otherness (Sonesh \& DeNisi, 2016; Toh \& DeNisi, 2007). Drawing from Toh and DeNisi (2007), we, thus, think of in-group collectivism as a barrier for expatriates' embeddedness. This argument is substantiated in related research. For instance, Varma et al. (2006) found that expatriates received less social support from HCN colleagues if they were considered out-group members and Shin, Morgeson and Campion (2007) showed that interpersonal skills are essential for expatriates in collectivist host countries. In addition, Garcia, Posthuma and Roehling (2009) demonstrated that individuals in in-group collectivist countries did not support hiring foreigners over nationals when job markets are tense.

Within TAT, the concept of situational facilitators imparts that situations exist where heightened demands of the environment facilitate the relevance and expression of a respective trait/ability (Tett \& Burnett, 2003; Tett et al., 2013). A facilitator-situation, hence, magnifies trait/ability relevant cues (Tett \& Burnett, 2003: 505). While we theorized that CQ in general is crucial for expatriates' embeddedness and to not stand out - using the figures metaphor - CQ's relevance and, therefore, effects on embeddedness should be amplified in difficult in-group collectivist host countries. This is 
grounded in the outlined challenges of collectivist environments and CQ as an ability that enables connecting with, fitting into, and engaging with the environment. As we argue that the behavioral value of CQ increases in in-group collectivist host countries, we conclude:

Hypothesis 2: In-group collectivism moderates the relationship between expatriate CQ and organizational embeddedness, insofar as the relationship between expatriate CQ and organizational embeddedness will be stronger in countries with high in-group collectivism.

\section{Immigration policies}

Countries implement immigration policies to regulate inflow and stay of foreigners. As such, immigration policies can be understood as "[...] a government's statements of what it intends to do or not do (including laws, regulations, decisions or orders) in regards to the selection, admission, settlement and deportation of foreign citizens residing in the country" (Bjerre, Helbling, Römer, \& Zobel, 2015: 559). Immigration policies are, thus, manifestations of countries' openness or reclusiveness towards foreigners on a socio-structural and legislative level. Whereas some countries have generous laws and support measures to accept and integrate foreigners, e.g. Germany, others, e.g. Kuwait, have very strict and reclusive policies (United Nations, 2013b). In this vein, the Kuwaiti government just recently announced that it intends to deport $50 \%$ of its expatriate population in the next years (Arab News, 2019). Discussing country level boundary conditions of expatriates' embeddedness, Chen and Shaffer (2017) theorized that host country openness can strengthen the effects of individual level antecedents on expatriates' embeddedness in the host organization. Vice versa, reclusiveness should be looked at as an impeding influence. So, what does reclusiveness mean for expatriates? For example, British selfinitiated expatriates working in engineering and law reported problems in having their qualifications recognized in Canada, requiring re-qualification to Canadian standards, even given the shared language and substantial shared institutional contexts of the UK and Canada (Harvey, 2012). On the flip side, the same study reported positive experiences of those who experienced openness from the host nation through recognition of their home country qualifications. Clearly the level of reclusiveness of a host country's formal institutions matters for expatriates.

In accordance with TAT (Tett \& Burnett, 2003; Tett et al., 2013), we conceptualize host country reclusiveness on the formal level, reflected in restrictive immigration policies, as a situational constraint. A constraint-situation, hence, negates the expression of a trait/ability (Tett \& Burnett, 2003: 505). In contrast to in-group collectivist orientations, which are enacted in interactions and are more suitable to be met with culturally intelligent behaviors, immigration policies are fixated, hardly malleable environmental properties that are outside expatriates' immediate sphere of influence. Following the principle of situational constraints in TAT, CQ will not be viewed as an adequate ability to deal with low openness on a formalized level, which reduces its relevance and negates its expression. Further, being in an unfriendly environment that imparts expatriates' presence is unwanted might also negate the expression of $\mathrm{CQ}$ by discouraging expatriates to exert culturally intelligent behaviors. In sum, we conclude:

Hypothesis 3: The degree of foreigner-friendly immigration policies moderates the relationship between expatriate CQ and organizational embeddedness, insofar as the relationship between expatriate $\mathrm{CQ}$ and organizational embeddedness will be weaker in countries with foreigner-unfriendly immigration policies.

\section{CQ and Knowledge Sharing}

Referring to Wang and Noe (2010: 117), knowledge is defined "[...] as information processed by individuals including ideas, facts, expertise, and judgments relevant for individual, team, and organizational performance"; and its sharing entails "[...] the provision of task information and know-how to help others and to collaborate with others to solve problems, develop new ideas." Knowledge sharing takes place between a source and a recipient of knowledge (Hislop, Bosua, \& Helms, 2018; Szulanski, 1996) and is viewed as a central activity by which employees can contribute to their organization's success (Jackson, Chuang, Harden, \& Jiang, 2006). For expatriates, nascent research has established that knowledge sharing is a key part of their job, i.e. expatriates are assigned to educate/manage local staff, fill knowledge gaps in 
skilled jobs in host countries, and develop global leadership competences (e.g., Edström \& Galbraith, 1977; Harzing, 2001; Heizmann et al., 2018; Wang et al., 2009). In this study, we focus on knowledge sharing between expatriates and their $\mathrm{HCN}$ colleagues.

In contrast to domestic settings, there are specific obstacles to the sharing of knowledge in a crosscultural work environment. Accordingly, many of the enablers of knowledge sharing in mono-cultural settings, such as interpersonal similarity, trust, a shared identity, as well as convergent cognitive styles and corresponding communication effectiveness (e.g., Chowdhury, 2005; Lin, Kao, \& Chang, 2010; Liu \& Phillips, 2011; Mesmer-Magnus \& DeChurch, 2009), are unlikely to be prominent between expatriates and HCN co-workers. Thus, differences between expatriates and HCN co-workers in terms of ethnicity, nationality, pay/status, and values (Toh \& DeNisi, 2007) reduce the prospects of developing a shared identity. Further, expatriates often are confronted with divergent ways of communication, for instance, indirect vs. direct communication (Bruning et al., 2012). This can facilitate misunderstandings and frustration in the sharing and decoding of knowledge (Peltokorpi, 2006). For example, Javidan, Stahl, Brodbeck, and Wilderom (2005) elaborate that highly formalized, structured, and organized transfer of knowledge emanating from a high uncertainty avoidance knowledge transferor might be very strenuous if the recipient of that knowledge was socialized in a low uncertainty avoidance culture. Likewise, analytical approaches to problems vary across cultures - while East Asians like to apply a holistic view; Westerners prefer to dissect problems into fragments (Nisbett, 2003). These incongruences in analytical strategies may lead to frustrations when expatriates and HCN colleagues share knowledge working on a task. Finally, situational feel is needed to assess when knowledge is shared best, as occasions and contexts for knowledge sharing also vary across cultures (Peltokorpi, 2006).

The outlined hurdles to knowledge sharing can be conceived of as particular demands of expatriates' job situations. The underlying nature of these challenges is cross-cultural. Therefore, as per TAT (Tett et al., 2013), CQ should have a high trait/ ability relevance for dealing with these challenges and for effectively engaging in knowledge sharing. This should lead to CQ's activation through its meta-cognition facet and subsequent expression of culturally intelligent behaviors. Once $\mathrm{CQ}$, as the corresponding type of intelligence to deal with the cross-cultural situation, takes cognitive focus, metacognition will direct attention to respective cultural knowledge and skills that can enable knowledge sharing (Thomas et al., 2008) - for instance, bringing to mind differences between low versus high context communication. Further, following Thomas et al. (2008, 2015), meta-cognition continues to monitor the situation by inhibiting inappropriate responses, such as emotional outbursts caused by frustration, that would negatively affect knowledge sharing activities and allows expatriates to learn from the present experience to become more effective in future knowledge sharing. Metacognition can, thus, also promote the synthetization of novel behaviors that fit specifically to the knowledge sharing context (Thomas et al., 2008). Further, we believe that working together with a culturally intelligent expatriate will also lead HCN co-workers to seek more interactions and to engage in higher levels of knowledge sharing. This can be explained by the establishment of affect-based trust between culturally intelligent expatriates and $\mathrm{HCN}$ co-workers. Accordingly, the research by Chua, Morris and Mor (2012) lends support to this contention. Chua et al. focused on the metacognition component of CQ and, inter alia, conducted an experimental study featuring individuals in culturally mixed dyads. As part of the experiment, individuals had to work on a creativity task. Their findings suggest that meta-cognition was positively related to affect-based trust and that affect-based trust mediated the effects of metacognition on idea sharing and creative performance in dyads if participants were given the opportunity to get to know each other on a personal level before working on the actual creativity task. In a similar vein, the research by Mor, Morris and Joh (2013) demonstrated a positive effect of meta-cognition on intercultural collaboration effectiveness mediated via enhanced cultural perspective taking. In sum, based on our theoretical rationale and related empirical evidence, we posit:

Hypothesis 4: Expatriate CQ relates positively to knowledge sharing.

\section{Organizational Embeddedness as a Mediator}

Within expatriation research, the study of mediators between CQ and performance-related outcomes has primarily focused on cross-cultural adjustment (e.g., Chen et al., 2010; Lee \& Sukoco, 2010; Malek \& Budhwar, 2013). In this sense, 
current understanding of further relevant intervening mechanisms that transmit the effects of CQ and additional vital outcome variables in the expatriation context is limited. Based on the prior developments of our conceptual model via TAT, we argue that organizational embeddedness functions as a mediator in the CQ-knowledge sharing association.

One of the constituent parts of embeddedness are the links that individuals share with other members of the organization (Mitchell et al., 2001). Usually, sharing of knowledge occurs through interactions (Ipe, 2003) and actors in a social environment, such as the organization, are carriers of knowledge (Granovetter, 1973). The vehicle through which knowledge becomes disseminated are the links or ties between individuals (Granovetter, 1973). As such, being embedded and having strong links with other members should enable knowledge sharing. Similarly, establishing a network with HCN coworkers will inform expatriates and co-workers on who knows what in the organization. Therefore, we argue that enhanced information on knowledge location will enable expatriates and co-workers to engage in more targeted and efficient knowledge sharing (Lauring \& Selmer, 2012). Further, motivational considerations are often involved in knowledge sharing. Thus, if individuals feel that the knowledge they possess is congruent with what is needed in the host location and helpful in promoting their careers and growth, the tendency to engage in knowledge sharing will be higher than when fit is poor. Moreover, if individuals enjoy the perks of their job, they will most likely be motivated to proactively engage in knowledge sharing to secure/advance their own career and contribute to the success of their organization. In sum, organizational embeddedness should be positively associated with knowledge sharing. Empirical evidence from related research supports this. Ng and Feldman (2010) found a positive relationship between organizational embeddedness and innovative behaviors in the domestic workplace. Since we propose that organizational embeddedness is enabled by CQ, we believe that high CQ expatriates will engage in more frequent knowledge sharing due to experiencing higher levels of embeddedness. This leads to:

Hypothesis 5: Organizational embeddedness mediates the effects of expatriate CQ on knowledge sharing.
Our conceptual model is depicted in Figure 1.

\section{METHODS}

\section{Sample}

Data were collected from November 2015 until September 2016. We collected questionnaires from expatriates located in 30 different host countries to enable us to conduct multi-level analyses. To avoid single organization bias, we surveyed expatriates from a broad spectrum of industries and organizations. With regards to country selection and the examination of country level effects, we used House et al.'s (2004) GLOBE-study which identified ten distinct cultural clusters, e.g. a Latin American, a Germanic, and a South Asian cluster, among others. To ensure the study's feasibility, we selected three countries from each cluster. Identification of expatriates in target countries was carried out by more than 20 research assistants who searched for expatriates' contact details on LinkedIn. Participation was voluntary and respondents were guaranteed confidentiality. In sum, we sent out 13,129 invitations to our initial survey and received 2103 usable questionnaires. However, for this study, we had to remove 206 individuals since their employment status, i.e. freelancer, self-employed, did not match the outline of this survey, as we were interested in expatriates who are employed by an organization. Thus, the final sample at time-point one (T1) for this study is comprised of $N=1897$ expatriates, which equates to a response rate of $14.4 \%$ (Table 1 shows a detailed overview of the sample distribution by country in $\mathrm{T} 1$ and $\mathrm{T} 2$ ). After a time-lag of approximately two months, we started our follow-up survey and contacted expatriates who had successfully completed our initial survey. To mitigate attrition in $\mathrm{T} 2$, we provided expatriates with a report of our T1-findings and further announced a lottery draw. The final sample size for $\mathrm{T} 2$ is $N=1327$, corresponding to a response rate of almost $70 \%$ compared to T1 (see: Table 1). The average cluster size per country in T2 is $N=44$.

In terms of demography, the final sample is comprised of $74.6 \%$ males. The average age in years is 38.92 ( $\mathrm{SD}=9.88$ years). In all, expatriates originating from 100 different nations participated in this study. German expatriates constitute the largest group with $N=205$, followed by expatriates from the UK $(N=134)$, and US-American expatriates $(N=111)$. Other larger groups include expatriates from Russia $(N=31)$, India $(N=28)$, or Brazil 


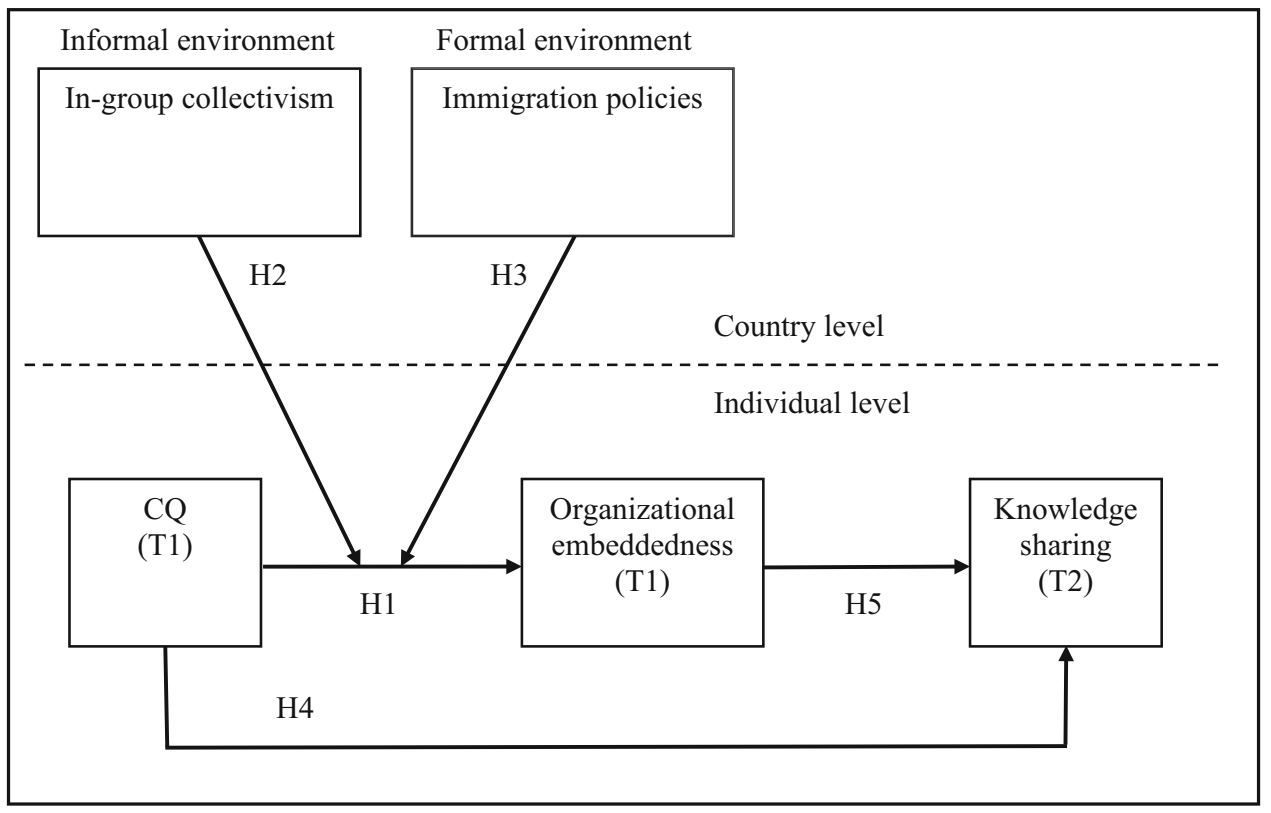

Figure 1 Conceptual model.

$(N=27)$. Among the respondents, $66.5 \%$ are married or live in a long-term relationship, with $44.4 \%$ having at least one child. 55.8\% are accompanied abroad by their spouse and $28.8 \%$ took their child(ren) with them abroad. On average, expatriates had been living for 6.14 years ( $\mathrm{SD}=6.48$ years) in the host country at $\mathrm{T} 1$. The average tenure is 6.09 years ( $\mathrm{SD}=6.50$ years). The surveyed expatriates work in many different industries with the largest groups, $13.7 \%$, employed in the communications sector, and $10.6 \%$ in high-tech manufacturing. Overall, the respondents are highly qualified with $94.9 \%$ holding a university degree, and $48.5 \%$ of expatriates working in higher management positions. The majority of expatriates are SIEs, i.e. $71.7 \%$, whereas $28.3 \%$ of the surveyed expatriates classified themselves as AEs. $42.4 \%$ of expatriates worked for local organizations, 38.9\% were employed by an organization from a third country, and $18.8 \%$ were working for an organization from their home country.

\section{Measures}

We used established scales in this survey. The data for measuring $\mathrm{CQ}$, organizational embeddedness and the control variables were collected in $\mathrm{T}$. Knowledge sharing, our dependent variable, was measured in T2. In-group collectivism and immigration policy indices were obtained from external sources.

\section{Independent variable}

CQ was measured using the ten-item inventory (SFCQ) developed by Thomas et al. (2015). The second-order structure integrates three sub-dimensions, i.e. cultural knowledge, cultural skills, cultural meta-cognition. Answers were provided on a seven-point Likert scale ( $1=$ strongly disagree, 7 = strongly agree). A sample item is "I have the ability to accurately understand the feelings of people from other cultures." Following prior research (Thomas et al., 2015), we used the composite scale. Cronbach's Alpha for the scale is 0.89 .

\section{Moderating variables}

In-group collectivism is a country level index obtained from House et al.'s (2004) GLOBE-study. The GLOBE-study examined nine cultural dimensions across 62 countries and surveyed 17,370 managers. GLOBE measured cultural dimensions in two domains, i.e. values (as things should be) and practices (as things are). Due to a possibly closer association to the day-to-day experiences of expatriates working in a foreign environment, we selected the practices domain of in-group collectivism for this study. In our sample, China is an example of a country with high in-group collectivism, Brazil is in the mid-field, and Denmark is a country with low in-group collectivism.

The second country level moderator depicting host countries' openness towards foreigners on the formal level, national immigration policies, is 
Table 1 Overview of response rates per country in time-point one and time-point two.

\begin{tabular}{|c|c|c|c|c|c|}
\hline Country & $\begin{array}{l}\text { Initial email } \\
\text { invitations }\end{array}$ & $\begin{array}{c}\text { Time-point } 1 \text { response } \\
\text { number }\end{array}$ & $\begin{array}{c}\text { Time-point } 1 \text { response } \\
\text { rate }(\%)\end{array}$ & $\begin{array}{c}\text { Time-point } 2 \text { response } \\
\text { number }\end{array}$ & $\begin{array}{c}\text { Time-point } 2 \text { response } \\
\text { rate }(\%)\end{array}$ \\
\hline Argentina & 469 & 55 & 11.73 & 35 & 63.63 \\
\hline Australia & 520 & 63 & 12.12 & 46 & 73.02 \\
\hline Austria & 532 & 128 & 24.06 & 97 & 75.78 \\
\hline Brazil & 220 & 27 & 12.27 & 20 & 74.07 \\
\hline China & 529 & 83 & 15.69 & 65 & 78.31 \\
\hline Denmark & 216 & 38 & 17.59 & 28 & 73.68 \\
\hline Finland & 520 & 94 & 18.08 & 73 & 77.66 \\
\hline France & 568 & 70 & 12.32 & 52 & 74.29 \\
\hline Germany & 518 & 93 & 17.95 & 62 & 66.66 \\
\hline Hungary & 550 & 95 & 17.27 & 70 & 73.68 \\
\hline India & 488 & 67 & 13.73 & 44 & 65.67 \\
\hline Indonesia & 464 & 71 & 15.30 & 48 & 67.61 \\
\hline Ireland & 379 & 51 & 13.46 & 31 & 60.78 \\
\hline Japan & 392 & 59 & 15.05 & 45 & 76.27 \\
\hline Kuwait & 359 & 21 & 5.85 & 14 & 66.66 \\
\hline Mexico & 294 & 55 & 18.71 & 32 & 58.18 \\
\hline Namibia & 204 & 26 & 12.75 & 21 & 80.77 \\
\hline Nigeria & 453 & 62 & 13.69 & 41 & 66.13 \\
\hline Poland & 381 & 40 & 10.50 & 30 & 75.00 \\
\hline Portugal & 402 & 69 & 17.16 & 52 & 75.36 \\
\hline Qatar & 383 & 47 & 12.27 & 27 & 57.45 \\
\hline Russia & 509 & 83 & 16.31 & 47 & 56.63 \\
\hline South Africa & 484 & 47 & 9.71 & 33 & 70.21 \\
\hline South Korea & 545 & 78 & 14.31 & 60 & 76.92 \\
\hline Spain & 475 & 45 & 9.47 & 32 & 71.11 \\
\hline Sweden & 393 & 99 & 25.19 & 72 & 72.73 \\
\hline Thailand & 466 & 62 & 13.30 & 46 & 74.19 \\
\hline The & 528 & 75 & 14.20 & 39 & 52.00 \\
\hline \multicolumn{6}{|l|}{ Netherlands } \\
\hline The USA & 531 & 39 & 7.34 & 26 & 66.66 \\
\hline Turkey & 357 & 55 & 15.41 & 39 & 70.91 \\
\hline
\end{tabular}

based on a report on international migration policies by the United Nations (2013a) and the associated wall chart publication (United Nations, 2013b). To our best knowledge, the report is the only comprehensive source for immigration policies across a wide range of nations. For instance, frequently used indices such as the MIPEX mostly cover Western, OECD countries and only offer limited to no information on the state of immigration policies in other parts of the world. Our calculation of this index is based on the inclusion of five indicators from the UN report. Two indicators capturing governmental immigration policies were coded using the following categories: no intervention, lower, maintain, increase. One indicator regarding governments' views on immigration was coded: too high, maintain, too low. Another indicator pertains to the measures governments implement to integrate non-nationals. The variable differentiates whether measures are implemented or not and is, thus, binary (yes/no). The last indicator captures differences in nationalization regulations. It distinguishes between no legal opportunities to become naturalized, restrictive regulations, for instance naturalization is only open to certain groups of foreigners or after a residency of ten years or longer, and less restrictive legal provisions. For each indicator, we assigned a ' 1 ' if countries had the most positive, i.e. foreignerfriendly, rating possible on the respective indicator suggesting an open and welcoming formal environment. If this was not the case, we assigned a ' 0 '. We added these scores up. Thus, scores could range between zero and five. Higher values indicate more open immigration policies. An example for a country with very open immigration policies is 
Sweden, Ireland is in the mid-field, and Kuwait is an example of a country with very restrictive immigration policies.

\section{Mediating variable}

Organizational embeddedness was captured by the adoption of items used by Tharenou and Caulfield (2010) and Mitchell et al. (2001). We asked individuals to think about their embeddedness in the host country organization and inquired about their perceptions of fit, links, and sacrifice. Respondents gave their answers on a seven-point Likert scale ( 1 = strongly disagree, 7 = strongly agree). A sample item (links) reads "I regularly interact with my coworkers". Following prior research (e.g., Allen \& Shanock, 2013; Kraimer, Shaffer, Harrison, \& Ren, 2012; Mitchell et al., 2001), we created a composite for organizational embeddedness. Cronbach's Alpha for the composite is 0.82. Since organizational embeddedness is a formative construct (Mitchell et al., 2001), Cronbach's Alpha is, however, not relevant (Allen \& Shanock, 2013).

\section{Dependent variable}

We used the knowledge sharing in the workplace scale from Minbaeva, Mäkelä, and Rabbiosi (2012). We applied the four-item scale to find out about the extent to which individuals had engaged in knowledge sharing with HCN colleagues and to which extent this knowledge had been used. Respondents could provide their answers on a seven-point Likert scale $(1=$ not at all, $7=$ to an extremely large extent). One sample item is "To what extent have colleagues gained knowledge from you?". The scale's Cronbach's Alpha is 0.79 .

\section{Control variables}

To rule out alternative explanations for organizational embeddedness and knowledge sharing, we controlled for gender $(0=$ female, $1=$ male $)$ since research has indicated that the expatriation experience and knowledge sharing can differ between men and women (Bader, Stoermer, Bader, \& Schuster, 2018, Nguyen, Nham, Froese, \& Malik, 2019). Further, we included age (in years) as a control variable. Prior research showed that age informs perceptions of individuals' ability and motivation to provide and receive knowledge and, consequently, actual knowledge sharing behaviors (Burmeister, Fasbender, \& Deller, 2018). Tenure (in years) was controlled for as research has shown a positive relationship with embeddedness (Peltokorpi, Allen, \& Froese, 2015) and a negative relationship with knowledge sharing (Sarti, 2018). Moreover, we controlled for effects associated with expatriation type $(0=\mathrm{SIE}, 1=\mathrm{AE})$ since differences in organizational embeddedness between these two types of expatriates have been identified in prior research (Biemann \& Andresen, 2010). In a related vein, we also controlled whether organizations were from the host country, a third country, or the home country $(0=$ local organization, $1=$ third country/home country organization). Additionally, we controlled for perceived organizational support (POS). We measured POS with five items from Eisenberger, Huntington, Hutchison and Sowa (1986) (Cronbach's Alpha =.91). POS has been found to affect knowledge sharing (e.g., Yang, van Rijn, \& Sanders, 2018) and to be correlated with employee embeddedness in domestic and international work contexts (e.g., Allen \& Shanock, 2013; Chen \& Shaffer, 2017). Finally, rank $(0=$ none/low managerial rank, 1 = upper middle/top level managerial rank) was included as a control to factor in differences in knowledge sharing behaviors across managerial levels (Riege, 2005).

\section{Preliminary Analyses}

We conducted confirmatory factor analysis (CFA) before testing our hypotheses. Following prior research (Allen \& Shanock, 2013), we did not include organizational embeddedness in these analyses as it is a formative construct. CQ was conceptualized as a second-order structure, whereas knowledge sharing and POS were conceptualized as first-order structures. We had to add two error-term correlations in the knowledge sharing and one error-term correlation in the meta-cognition subdimension of CQ due to high content overlap. After this, the results from CFA indicated that the measurement model fit the data well: $\chi^{2}=556.129 ; \quad \mathrm{DF}=143 ; \quad p<0.001 ; \quad \mathrm{CMIN} / \mathrm{DF}=$ 3.889; $\quad$ CFI $=0.972 ; \quad$ TLI $=0.966 ; \quad$ RMSEA $=0.047$ (see for thresholds for fit indices: Byrne, 2001). Furthermore, all items loaded on their respective factor significantly with loadings higher than 0.50 and the average variance extracted by each factor was higher than any of the squared correlations between latent constructs, which suggests discriminant validity (Fornell \& Larcker, 1981). As a post hoc measure to examine if common method variance was distorting our data, we used the common latent factor method (Podsakoff, MackKenzie, Lee, $\&$ Podsakoff, 2003). The results indicate that common method variance was not severely affecting our data, with the common variance estimate being 
clearly below common thresholds (Eichhorn, 2014).

Further, as our data were collected at two timepoints, we investigated the existence of attrition bias by following the procedure recommended by Miller and Hollist (2007). We checked for differences in key sample characteristics, e.g. gender, age, expatriate type, rank, and expatriate origin, between the participants that dropped out after time-point one and those who completed both survey waves. The results suggest that there is no attrition bias related to gender, rank, and expatriation type. However, expatriates' age $(B=0.016$, $\mathrm{SE}=0.006, \operatorname{Exp}(B)=1.016, p=0.003)$ and expatriate origin $(B=0.259, \mathrm{SE}=0.107, \operatorname{Exp}(B)=1.295$, $p=0.016)$ were statistically significant, implying that older expatriates and expatriates who originated from Western countries were more likely to take our follow-up survey. Subsequently, we examined if attrition bias was influencing the internal validity of our study by comparing the correlations of our focal variables in time-point one between the overall sample and the two-wave sample. Following Miller and Hollist (2007), we compared correlation coefficients by the use of Fisher's z-test. The results of this analysis yielded no significant differences between correlations, which implies that the internal validity of our study is not severely affected by attrition bias.

\section{RESULTS}

We analyzed hypotheses simultaneously using a multi-level path model. We used the software package Mplus 7.0 and applied the maximum likelihood robust estimator. Given the requirement in multi-level analysis that at least $5 \%$ of the variance explained in the dependent lower level variable (Heck \& Thomas, 2009), needs to be accounted for by a higher level, we calculated the null model for organizational embeddedness. The null model dissects the variance in the respective variable in its within- and between-level parts. The results show that this requirement was met, i.e. $\mathrm{ICC}_{1}=0.065(6.5 \%$ of variance explained by country level variables), and the integration of country level variables is thus, warranted. Table 2 shows the means, standard deviations and correlations between the variables included in this study.

We now turn to testing our hypotheses. In H1, we hypothesized a positive relationship between CQ and organizational embeddedness. This hypothesis was confirmed $(\gamma=0.143, p<0.001$; see: Table 3). In $\mathrm{H} 2$, we postulated a cross-level interaction between CQ and in-group collectivism. Again, this hypothesis was supported $(\gamma=0.070$, $p=0.036)$. Next, in H3, we tested for a cross-level interaction between CQ and the country level index of immigration policies. This hypothesis was rejected $(\gamma=0.017, p=0.564)$ Then, we continued by testing $\mathrm{H} 4$ which suggested a positive association between CQ and knowledge sharing. Results of our analysis corroborate $\mathrm{H} 4(\gamma=0.182$, $p<0.001)$. Finally, we examined H5 which posited that organizational embeddedness functions as a mediator in the relationship between CQ and knowledge sharing. Results of our analysis support H5 $(\gamma=0.037, p<0.001,95 \%$ CI [0.021; 0.053]).

To better understand the inherent nature of the identified significant cross-level interaction, we followed Aiken and West (1991) and visualized the interaction by creating an interaction plot (Figure 2). Interpretation of Figure 2 suggests that the relationship between CQ and organizational embeddedness is stronger in countries with a high degree of in-group collectivism. As part of additional analyses, we also investigated the existence of a moderated mediation at two levels of in-group collectivism, i.e. $+1 \mathrm{SD}$ above the mean, and -1 $\mathrm{SD}$ below the mean. The obtained results indicate that the mediation is significant at both levels of the moderator; however, it is stronger at high levels of in-group collectivism: $(+1$ SD: $\gamma=0.050$, $p<0.001 ; \quad 95 \%$ CI $[0.028 ; 0.072] ;-1 \quad$ SD: $\gamma=0.024, p=0.013 ; 95 \%$ CI $[0.005 ; 0.043])$.

\section{DISCUSSION}

In this study, we set out to examine if the importance of expatriates' cultural intelligence (CQ) in establishing organizational embeddedness in the host country organization differs as a function of host countries' openness towards foreigners. Based on institutional theory, we distinguished between host countries' openness on an informal/formal level and applied the typology of situations as facilitator or constraint from trait activation theory. In line with our hypotheses, we found that CQ exerts a positive main effect on organizational embeddedness and that CQ's role as a predictor of organizational embeddedness is facilitated in host countries with a strong in-group collectivist orientation. While we proposed that CQ can help in dealing with host countries' reclusiveness on an informal level, we postulated that CQ's usefulness is constrained when it comes to handling 
Table 2 Means, standard deviations, and correlations.

\begin{tabular}{|c|c|c|c|c|c|c|c|c|c|c|c|c|}
\hline Variables & Mean & SD & 1 & 2 & 3 & 4 & 5 & 6 & 7 & 8 & 9 & 10 \\
\hline \multicolumn{13}{|l|}{ Individual level variables } \\
\hline 1. Gender & 0.75 & 0.44 & 1 & & & & & & & & & \\
\hline 2. Age & 38.92 & 9.88 & 0.211 & 1 & & & & & & & & \\
\hline 3. Tenure & 6.09 & 6.50 & 0.147 & 0.505 & 1 & & & & & & & \\
\hline $\begin{array}{l}\text { 4. Local vs. third/home country } \\
\text { organization dummy }\end{array}$ & 0.58 & 0.49 & 0.033 & 0.031 & 0.189 & 1 & & & & & & \\
\hline 5. Expatriation type & 0.28 & 0.45 & 0.052 & 0.096 & 0.479 & 0.346 & 1 & & & & & \\
\hline 6. Rank & 0.49 & 0.50 & 0.144 & 0.372 & 0.303 & 0.149 & 0.186 & 1 & & & & \\
\hline 7. Perceived organizational support & 5.02 & 1.20 & -0.019 & 0.026 & 0.067 & 0.036 & 0.081 & 0.179 & 1 & & & \\
\hline 8. $C Q$ & 5.61 & 0.77 & -0.048 & 0.028 & 0.048 & 0.022 & 0.016 & 0.095 & 0.127 & 1 & & \\
\hline 9. Organizational embeddedness & 4.88 & 0.96 & 0.066 & 0.072 & 0.106 & 0.006 & 0.022 & 0.159 & 0.432 & 0.163 & 1 & \\
\hline 10. Knowledge sharing & 5.00 & 0.88 & 0.054 & 0.108 & 0.149 & 0.094 & 0.113 & 0.201 & 0.273 & 0.228 & 0.351 & 1 \\
\hline \multicolumn{13}{|l|}{ Country level variables } \\
\hline 1. In-group collectivism & 5.04 & 0.72 & 1 & & & & & & & & & \\
\hline 2. Immigration policies & 2.77 & 1.19 & -0.226 & 1 & & & & & & & & \\
\hline
\end{tabular}

$N=1327$ on the individual level. All correlations with absolute value larger than 0.053 are significant at the $p<0.05$ level.

$N=30$ on the country level. All correlations with absolute value larger than 0.362 are significant at the $p<0.05$ level.

Table 3 Results of multilevel analysis.

\begin{tabular}{|c|c|c|c|c|}
\hline \multirow[t]{3}{*}{ Variables } & \multicolumn{4}{|c|}{ Model } \\
\hline & \multicolumn{2}{|c|}{ Org. embeddedness } & \multicolumn{2}{|c|}{ Knowledge sharing } \\
\hline & Coefficient & $p$ & Coefficient & $p$ \\
\hline \multicolumn{5}{|l|}{ Controls } \\
\hline Gender & $0.151(0.074)$ & 0.041 & $0.069(0.052)$ & 0.185 \\
\hline Age & $-0.003(0.003)$ & 0.216 & $0.002(0.002)$ & 0.386 \\
\hline Tenure & $0.016(0.005)$ & 0.003 & $0.004(0.004)$ & 0.346 \\
\hline Local versus third/home country organization dummy & $0.007(0.059)$ & 0.910 & $0.091(0.036)$ & 0.012 \\
\hline Expatriation type & $-0.164(0.041)$ & 0.000 & $0.103(0.039)$ & 0.008 \\
\hline Rank & $0.069(0.064)$ & 0.283 & $0.138(0.051)$ & 0.007 \\
\hline \multicolumn{5}{|l|}{ Individual level predictors } \\
\hline CQ & $0.143(0.028)$ & 0.000 & $0.182(0.042)$ & 0.000 \\
\hline Organizational embeddedness & & & $0.258(0.027)$ & 0.000 \\
\hline \multicolumn{5}{|l|}{ Country level predictors } \\
\hline In-group collectivism & $-0.076(0.077)$ & 0.327 & & \\
\hline Immigration policies & $0.042(0.042)$ & 0.321 & & \\
\hline \multicolumn{5}{|l|}{ Cross-level interactions } \\
\hline CQ $X$ in-group collectivism & $0.070(0.033)$ & 0.036 & & \\
\hline $\mathrm{CQ} X$ foreigner-friendly immigration policies & $0.017(0.029)$ & 0.564 & & \\
\hline Pseudo $R^{2}$ (Snijders and Bosker) & $21 \%$ & & $19 \%$ & \\
\hline
\end{tabular}

Individual level $N=1327$. Country level $N=30$.

Predictor variables on the individual level were group-mean centered. Country level predictors variables were grand-mean centered.

Standard errors are provided in parentheses.

formalized barriers on the sociopolitical and legislative level. However, we found no evidence for a significant cross-level interaction between immigration policies and CQ. Furthermore, analyses indicate that high CQ expatriates are involved in more knowledge sharing in the foreign workplace and that organizational embeddedness functions as an intervening variable in the association between $\mathrm{CQ}$ and knowledge sharing. The implications of these findings for theory and practice are discussed next. 


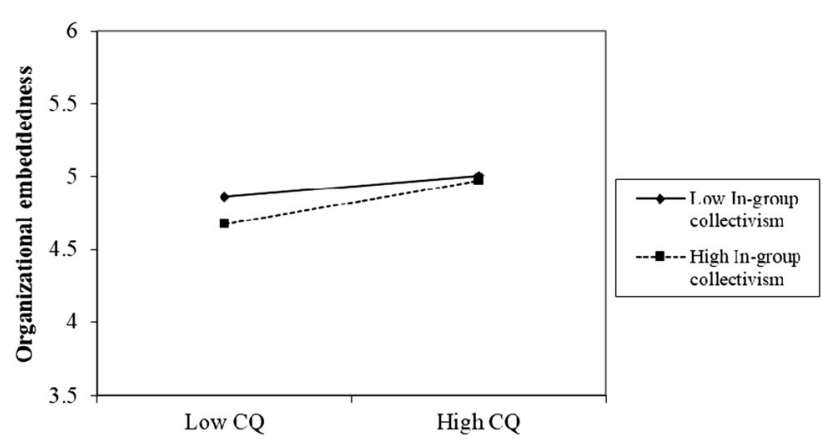

Figure 2 Interaction plot of CQ and in-group collectivism.

\section{Theoretical Implications}

The main theoretical contribution of this study is the contextualization of CQ. Extending prior research (e.g., Chen et al., 2010), we distinguished between two different types of host country environments - the informal and formal environment (North, 1990) - and integrated the facilitator/constraint idea from TAT (Tett \& Burnett, 2003; Tett et al., 2013) to explain why CQ might be more or less relevant across host country contexts. Thus far, no study has investigated how different types of specific environments might promote or reduce the behavioral value of culturally intelligent behaviors. This is a fundamental limitation to research on CQ (Ott \& Michailova, 2018) and this study intended to challenge this limitation. Our findings showed that CQ interacts with the tribulations posed by the informal environment. Consistent with TAT, findings imply that a difficult informal environment, represented by in-group collectivism in this study, comes with heightened demands that magnify the relevance of culturally intelligent behaviors in establishing organizational embeddedness. This provides a preliminary answer to the question raised by Ott and Michailova (2018) regarding the utility of CQ across contexts. Accordingly, we can tentatively infer that CQ does shine in informal, cultural environments that are associated with potentially serious complications for individuals new to the environment. Using TAT-terminology (Tett \& Burnett, 2003), these environments represent facilitators that amplify the value of CQ. While existing research focused on cultural distance as an enhancer/inhibitor of the effects of CQ (Chen et al., 2010; Kim et al., 2008; Zhang, 2013) and has produced inconsistent findings (Ott \& Michailova, 2018), an implication from this study is to rather examine CQ's interplay with context by selecting specific cultural value dimensions that closely correspond to the outcome of interest. Such a tailored approach might be better suited and might provide greater detail and granularity of when CQ does and does not interact with context. Based on our classification of environments, we further centered on immigration policies - the counterpart to in-group collectivism on the formal level. We argued that foreigner-unfriendly immigration policies function as a situational constraint to CQ (Tett $\&$ Burnett, 2003). Based on this contention, we theorized that CQ as an ability to be effective in cross-cultural interactions (Thomas et al., 2015), will be of little relevance to deal with reclusiveness on a socio-structural and legislative level. However, no cross-level interaction was identified. This indicates that it is primarily the informal environment that serves as a boundary condition of CQ' effects and that the effects of CQ on organizational embeddedness remain relatively unaffected by the formal environment. An intriguing implication of this finding is that although in-group collectivism and immigration policies are proxies for host countries' openness to foreigners, it is the particular Gestalt of the environment (informal vs. formal) that determines if CQ will interact with the environment or not.

Second, by examining CQ as an antecedent of expatriates' organizational embeddedness, we followed Ren et al. (2014) who suggested that expatriates are not bound to merely adjust to their environment but also to proactively embed. This is associated with a change in perspective that positions expatriates as agents who can exert influence on their own fate in the host country and are not limited to exclusively responding to the stressors within their environment (Ren et al. 2014). While adapting to the environment certainly continues to be a vital part of expatriates' working and living realities abroad, we hypothesized that CQ not only assists adapting to but also crafting of expatriates' situation in the host organization - for instance, by creating links with local co-workers, by establishing better fit, and by exploiting the opportunities of the environment. Our findings lend support for this positive effect on embeddedness and, therefore, complement nascent research that primarily centered on CQ and cross-cultural adjustment (e.g., Chen et al., 2010; Lee \& Sukoco, 2010; Malek \& Budhwar, 2013). Similarly, we drew attention to an important but surprisingly neglected variable in the context of expatriation research: expatriates' engagement in knowledge sharing in the foreign workplace. Integrating arguments from research on knowledge sharing in mono- and multicultural 
work environments, we outlined the potential challenges to knowledge sharing in expatriates' workplaces and positioned CQ as an ability that bridges problematic cross-cultural divides. In fact, our results solidify our hypothesis and demonstrate that CQ enables knowledge sharing. Given the relevance of knowledge sharing for expatriates (e.g., Edström \& Galbraith, 1977; Harzing, 2001; Heizmann et al., 2018; Wang et al., 2009), the identification of this relationship represents an important finding. Additionally, by delineating the mediating role of organizational embeddedness, we contribute to the disentanglement of the mechanisms by which CQ relates to crucial expatriate outcomes above and beyond cross-cultural adjustment (Ott \& Michailova, 2018).

Third, with regards to TAT, our study offers two vital contributions. Firstly, our study applies and tests one of the recent extensions within TAT (Tett et al., 2013). In one of their earlier works on TAT, Tett and Burnett (2003) reasoned that major processes underlying the activation of traits could also be applied to the priming and expression of individual knowledge, skills, and abilities, such as CQ. However, this idea, while already incorporated in earlier publications, has been a peripheral element in the academic use of TAT - suggesting that one critical explanatory element of the framework has largely gone unnoticed. Later on, Tett et al. (2013) incorporated abilities as a more prominent component in the extended TAT-framework. By using TAT as an explanatory framework in the context of $\mathrm{CQ}$, our study substantiates the later refinements to TAT and consolidates TAT's relevance in explaining interactions between individuals' knowledge, skills, abilities and situational properties. It, thus, shows a way forward on how to fully harness the explanatory potential of TAT and expands the related literatures centering on abilities (e.g., Anderson, Spataro, \& Flynn, 2008; Farh, Seo, \& Tesluk, 2012; Hochwarter, Witt, Treadway, \& Ferris, 2006). Secondly, our study expands TAT by introducing the host country context as a moderator. While situational cues residing on the task, social, and organizational level might be the most critical influence on the activation and expression of traits and abilities in domestic context, we provided a tailored account of how the host country environment influences the strength of the relationship between CQ and organizational embeddedness for expatriates. Leaving the home country context and being exposed to the host country environment is one, if not the most outstanding part of the expatriation experience (Oberg, 1960). Hence, we incorporated the host country environment as a situational property and added another layer of investigation to TAT, i.e. the country level. We hope that future research will acknowledge that TAT can indeed be used to elucidate the influence of country level properties and increasingly consider phenomena in international human resource management or cross-cultural management through the TAT-lens.

Fourth, our findings enhance research on embeddedness by identifying boundary conditions regarding the establishment of embeddedness in a foreign country. To our best knowledge, theorizations of embeddedness and recent discussions (Lee et al., 2014; Zhang, Fried, \& Griffeth, 2012) have largely been silent about boundary conditions that facilitate or impede becoming embedded. By investigating host country context as a moderator in the case of expatriates, our study provides vital impulses to embeddedness research to further pay attention to antecedents and moderators of embeddedness on several levels. It also expands the few studies integrating an international dimension in research on embeddedness (Ramesh \& Gelfand, 2010). Additionally, our study informs current thinking about the role of individual differences that help individuals to become immersed in their environment or that stand in their way. As Ng and Feldman (2011) noted, knowledge of individual level predictors of embeddedness is limited and, accordingly, the thrust of existing research focused on outcomes and/or moderators of embeddedness (Jiang, Lui, McKay, Lee, \& Mitchell, 2012; Lee et al., 2014; Peltokorpi et al., 2015). The current study left the well-trodden, CQ-cross-cultural adjustment paradigm and positioned CQ as an environment shaping ability that enables individuals to proactively embed. Our finding lent support to our proposition and, thus, enriches embeddedness research by highlighting the role of individual level antecedents.

\section{Managerial Implications}

Our study also has managerial implications. First, it emphasizes the beneficial role of CQ. Thus, we recommend that in the recruiting and pre-assignment stages, internationally operating organizations should include measures capturing CQ to assess (future) expatriates' CQ. An appropriate and feasible measure is the short inventory (SFCQ) by Thomas et al. (2015) that we applied in this study. In addition to selection, organizations should 
develop CQ of their employees. An avenue for facilitating CQ in employees is to encourage international exposure and international experience in general (e.g., Li, Mobley, \& Kelly, 2012; Takeuchi, Tesluk, Yun, \& Lepak, 2005). Similarly, organizations should implement cross-cultural training that features a contact component with culturally dissimilar others to foster the development of CQ (MacNab, Brislin, \& Worthley, 2012). Additionally, working in global virtual teams has been demonstrated to be beneficial for eliciting and enhancing CQ in employees (Erez, Lisak, Harush, Glikson, Nouri, \& Shokef, 2013).

Second, our study shows that CQ is particularly important for the establishment of organizational embeddedness in in-group collectivist host countries. Therefore, HR managers and global mobility officers need to be sensitized toward the challenges of in-group oriented host destinations and the interplay with $\mathrm{CQ}$ as a vital characteristic of individuals. To convey this, organizations can offer or even prescribe participation in related simulations. A simulation game that has specifically been designed to facilitate sensitization to the hurdles posed by cultural values, such as in-group collectivism, is the OASISTAN simulation (De Jong \& Warmelink, 2017). Coaches in charge of conducting these simulations can further be asked to tailor such simulations and emphasize the salience of ingroup orientations as an element of the simulation, if wished. Another avenue of how to increase sensitization is to make use of first-hand experiences and learn about viable problem solutions from repatriates returning from assignments in ingroup collectivist host countries. In addition, shortterm stints of one to three months, that encompass full involvement in a work project in a foreign subsidiary located in a high in-group collectivist country, are another way of how to foster awareness of the challenges of high-in group collectivist countries. In sum, we believe that knowledge of and exposure to in-group collectivist value orientations can impart the relevance of CQ for creating embeddedness in the host location to HR managers, global mobility officers, and expatriates. As such, these individuals will be able to discover the benefits of CQ as a critical ability to bridge divides between expatriates and local colleagues, to understand the importance of in-group norms, to not take locals' reserved attitudes towards outsiders personally, and to avoid common pitfalls that might disgruntle HCN colleagues.

\section{Limitations and Avenues for Future Research}

The findings of this study need to be interpreted in the light of its limitations. First, the obtained effect sizes were rather modest. While this is not uncommon for multi-level studies (e.g., Dastmalchian, Bacon, \& McNeil, 2020; Smale et al., 2019), we recommend that future research complements our model and integrates additional levels of analysis in particular, the organizational level. Future research could consider organizational socialization tactics that have been shown to be a vital predictor of organizational embeddedness in domestic contexts (Allen, 2006; Allen \& Shanock, 2013), or draw inspiration from the diversity literature and zoom in on the effects of an inclusive organizational climate (Nishii, 2013; Shore, Randel, Chung, Dean, Holcombe Ehrhart, \& Singh, 2011). Within a threelevel model, such organizational level variables could serve as connecting elements that bridge openness towards foreigners on the national level and expatriates' corresponding in- and out-group experiences in the workplace. Further, we think that exploring mediators between CQ and organizational embeddedness poses an intriguing future avenue. In this regard, CQ might be looked upon as a resource conserving or even resource enhancing factor that enables expatriates to assert their own interests in the host organization in smart ways. Therefore, being culturally intelligent could support expatriates in crafting favorable employment deals which should consequently strengthen their embeddedness (Ng \& Feldman, 2011). Second, our dependent variable, knowledge sharing is a selfreported measure. To better account for the interpersonal nature of knowledge sharing, future studies should aspire to gather dyadic data, e.g. from expatriates and HCN colleagues. This would also allow exploring for whom CQ matters more in expatriate-local knowledge sharing dyads and to advance understanding of potential mediators in the CQ-knowledge sharing link. For instance, exertion of culturally intelligent behaviors by an expatriate might create perceptions with $\mathrm{HCN}$ colleagues that this expatriate is easy and efficient to work with and suggests convergent cognitive styles. In turn, this could lead HCN colleagues to engage in more knowledge sharing activities with the expatriate. Likewise, future studies could further explore knowledge sharing by investigating potential variations depending on the composition of knowledge sharing dyads, e.g. looking at expatriate-subordinate HCN dyads or expatriate- 
superior HCN dyads. Third, in this study we focused on proactive embedment instead of reactive cross-cultural adjustment as a mediator in the association between CQ and knowledge sharing. Prior research mainly considered cross-cultural adjustment as a mediating variable between CQ and performance-related outcomes of expatriates (Chen et al., 2010; Lee \& Sukoco, 2010; Malek \& Budhwar, 2013). To triangulate the relative importance of proactive embedment and reactive crosscultural adjustment as intervening mechanisms between CQ and knowledge sharing, we recommend that future research collects data on both variables and compares their respective indirect effects. Fourth, our findings might be influenced by common method bias. To mitigate common method bias ex ante, we designed a cross-lagged survey and also integrated external country level data in our model. In addition, post hoc statistical tests suggest that common method bias is not a serious issue in our data. Nevertheless, to improve subsequent research designs, future studies are advised to collect data at multiple time-points and from multiple sources.

\section{CONCLUSION}

This study advanced our understanding of how the effects of expatriates' CQ hinge on host country contexts. By distinguishing between informal and

\section{REFERENCES}

Aiken, L. S., \& West, S. G. 1991. Multiple regression: Testing and interpreting interactions. Thousand Oaks, CA: Sage.

Allen, D. G. 2006. Do organizational socialization tactics influence newcomer embeddedness and turnover? Journal of Management, 32(2): 237-256.

Allen, D. G., \& Shanock, L. R. 2013. Perceived organizational support and embeddedness as key mechanisms connecting socialization tactics to commitment and turnover among new employees. Journal of Organizational Behavior, 34(3): 350-369.

Anderson, C., Spataro, S. E., \& Flynn, F. J. 2008. Personality and organizational culture as determinants of influence. The Journal of Applied Psychology, 93(3): 702-710.

Ang, S., Van Dyne, L., \& Koh, C. 2006. Personality correlates of the four-factor model of cultural intelligence. Group and Organization Management, 31(1): 100-123.

Ang, S., Van Dyne, L., Koh, C., Ng, K. Y., Templer, K. J., Tay, C., et al. 2007. Cultural intelligence: Its measurement and effects on cultural judgment and decision making, cultural adaptation and task performance. Management and Organization Review, 3(3): 335-371.

Arab News. 2019. Kuwaiti MPs call for $50 \%$ of expats to be deported. Retrieved June 30, 2019, from http://www. arabnews.com/node/1465451/business-economy.

Bader, A. K., Froese, F. J., Achteresch, A., \& Behrens, S. 2017. Expatriates' influence on the affective commitment of host country nationals in China: The moderating effects of formal host country environments, this study adopted a novel fine-grained perspective on the utility and limits of CQ. It, thus, delivers food for thought on a subtler treatment of host country boundary conditions in expatriation research in general and CQ specifically. This study also contributes to trait activation theory by adding another layer of investigation and by harnessing the further development of the explanatory power of the theory. The demonstration of the positive effects of CQ on organizational embeddedness and knowledge sharing and investigation of moderating influences provide researchers further insights regarding individual level precursors and mechanisms underlying successful expatriation. We thus believe that the findings of this study are important and interesting to researchers and practitioners in expatriate management.

\section{FUNDING}

Open access funding provided by Projekt DEAL. We thank anonymous referees for constructive comments.

individual values and status characteristics. European Journal of International Management, 11(2): 181-200.

Bader, B., Stoermer, S., Bader, A. K., \& Schuster, T. 2018. Institutional discrimination of women and workplace harassment of female expatriates: Evidence from 25 host countries. Journal of Global Mobility, 6(1): 40-58.

Bhaskar-Shrinivas, P., Harrison, D. A., Shaffer, M. A., \& Luk, D. M. 2005. Input-based and time-based models of international adjustment: Meta-analytic evidence and theoretical extensions. Academy of Management Journal, 48(2): 257-281.

Biemann, T., \& Andresen, M. 2010. Self-initiated foreign expatriates versus assigned expatriates. Journal of Managerial Psychology, 25(4): 430-448.

Bjerre, L., Helbling, M., Römer, F., \& Zobel, M. 2015. Conceptualizing and measuring immigration policies. A comparative perspective. International Migration Review, 49(3): 555-600.

Black, J. S., Mendenhall, M., \& Oddou, G. 1991. Toward a comprehensive model of international adjustment: An integration of multiple theoretical perspectives. Academy of Management Review, 16(2): 291-317.

Bolino, M. C., \& Feldman, D. C. 2000. The antecedents and consequences of underemployment among expatriates. Journal of Organizational Behavior, 21(8): 889-911.

Bruning, N. S., Sonpar, K., \& Wang, X. 2012. Host-country national networks and expatriate effectiveness. A mixedmethods study. Journal of International Business Studies, 43(4): 444-450. 
Bücker, J., Furrer, O., \& Lin, Y. 2015. Measuring cultural intelligence (CQ). A new test of the $C Q$ scale. International Journal of Cross Cultural Management, 15(3): 259-284.

Burmeister, A., Fasbender, U., \& Deller, J. 2018. Being perceived as a knowledge sender or knowledge receiver: A multistudy investigation of the effect of age on knowledge transfer. Journal of Occupational and Organizational Psychology, 91(3): 518-545.

Byrne, B. M. 2001. Structural equation modeling with AMOS: Basic concepts, applications, and programming. Mahwah, NJ: Lawrence Erlbaum Associates.

Chang, Y.-Y., Gong, Y., \& Peng, M. W. 2012. Expatriate knowledge transfer, subsidiary absorptive capacity, and subsidiary performance. Academy of Management Journal, 55(4): 927-948.

Chen, G., Kirkman, B. L., Kim, K., Farh, C. I., \& Tangirala, S. 2010. When does cross-cultural motivation enhance expatriate effectiveness? A multilevel investigation of the moderating roles of subsidiary support and cultural distance. Academy of Management Journal, 53(5): 1110-1130.

Chen, M.-L., \& Lin, C. P. 2013. Assessing the effects of cultural intelligence on team knowledge sharing from a socio-cognitive perspective. Human Resource Management, 52(5): 675-695.

Chen, Y. P., \& Shaffer, M. A. 2017. The influences of perceived organizational support and motivation on self-initiated expatriates' organizational and community embeddedness. Journal of World Business, 52(2): 197-208.

Chowdhury, S. 2005. The role of affect- and cognition-based trust in complex knowledge sharing. Journal of Managerial Issues, 17(3): 310-326.

Chua, R. Y. J., Morris, M. W., \& Mor, S. 2012. Collaborating across cultures: Cultural metacognition and affect-based trust in creative collaboration. Organizational Behavior and Human Decision Processes, 118(2): 116-131.

Dastmalchian, A., Bacon, N., McNeil, N., et al. 2020. Highperformance work systems and organizational performance across societal cultures. Journal of International Business Studies, 51: 353-388.

De Jong, M., \& Warmelink, H. 2017. Oasistan: An intercultural role-playing simulation game to recognize cultural dimensions. Simulation \& Gaming, 48(2): 178-198.

Earley, P. C. 2002. Redefining interactions across cultures and organizations: Moving forward with cultural intelligence. Research in Organizational Behavior, 24: 271-299.

Earley, P. C., \& Ang, S. 2003. Cultural intelligence: Individual interactions across cultures. Stanford, CA: Stanford University Press.

Edström, A., \& Galbraith, J. R. 1977. Transfer of managers as a coordination and control strategy in multinational organizations. Administrative Science Quarterly, 22(2): 248-263.

Eichhorn, B. R. 2014. Common method variance techniques. Cleveland State University, Department of Operations \& Supply Chain Management. Cleveland, OH: SAS Institute Inc.

Eisenberger, R., Huntingtion, R., Hutchison, S., \& Sowa, D. 1986. Perceived organizational support. Journal of Applied Psychology, 71(3): 500-507.

Elenkov, D. S., \& Manev, I. M. 2009. Senior expatriate leadership's effects on innovation and the role of cultural intelligence. Journal of World Business, 44(4): 357-369.

Erez, M., Lisak, A., Harush, R., Glikson, E., Nouri, R., \& Shokef, E. 2013. Going global: Developing management students' cultural intelligence and global identity in culturally diverse virtual teams. Academy of Management Learning \& Education, 12(3): 330-355

Farh, C. I., Bartol, K. M., Shapiro, D. L., \& Shin, J. 2010. Networking abroad: A process model of how expatriates form support ties to facilitate adjustment. Academy of Management Review, 35(3): 434-454.

Farh, C. I., Seo, M.-G., \& Tesluk, P. E. 2012. Emotional intelligence, teamwork effectiveness, and job performance.
The moderating role of job context. Journal of Applied Psychology, 97(4): 890-900.

Firth, B. M., Chen, G., Kirkman, B. L., \& Kim, K. 2014. Newcomers abroad: Expatriate adaptation during early phases of international assignments. Academy of Management Journal, 57(1): 280-300.

Fornell, C., \& Larcker, D. F. 1981. Structural equation models with unobservable variables and measurement error: Algebra and statistics. Journal of Marketing Research, 18(3): 382-388.

Froese, F. J., Kim, K., \& Eng, A. 2016. Language, cultural intelligence, and inpatriate turnover intentions: Leveraging values in multinational corporations through inpatriates. Management International Review, 56: 283-301.

Fu, C. K. \& Shaffer M. A. 2008. Socialization tactics, fit, and expatriate outcomes. In Academy of management proceeding (No.1: 1-6). Briarcliff Manor, NY: Academy of Management.

García, M. F., Posthuma, R. A., \& Roehling, M. V. 2009. Comparing preferences for employing males and nationals across countries. Extending relational models and social dominance theory. International Journal of Human Resource Management, 20(12): 2471-2493.

Granovetter, M. S. 1973. The strength of weak ties. American Journal of Sociology, 78(6): 1360-1380.

Guang, X., \& Charoensukmongkol, P. 2020. The effects of cultural intelligence on leadership performance among Chinese expatriates working in Thailand. Asian Business \& Management. https://doi.org/10.1057/s41291-020-00112-4.

Guð̋mundsdóttir, S. 2015. Nordic expatriates in the US. The relationship between cultural intelligence and adjustment. International Journal of Intercultural Relations, 47: 175-186.

Harvey, W. S. 2012. Labour market experiences of skilled British migrants in Vancouver. Employee Relations, 34(6): 658-669.

Harzing, A. W. 2001. Of bears, bumble-bees, and spiders: The role of expatriates in controlling foreign subsidiaries. Journal of World Business, 36(4): 366-379.

Harzing, A. W., Pudelko, M., \& Reiche, B. S. 2016. The bridging role of expatriates and inpatriates in knowledge transfer in multinational corporations. Human Resource Management, 55(4): 679-695.

Heck, R. H., \& Thomas, S. L. 2009. An introduction to multilevel modeling techniques (2nd ed.). New York: Routledge.

Heizmann, H., Fee, A., \& Gray, S. J. 2018. Intercultural knowledge sharing between expatriates and host-country nationals in Vietnam: A practice-based study of communicative relations and power dynamics. Journal of International Management, 24(1): 16-32.

Hislop, D., Bosua, R., \& Helms, R. 2018. Knowledge management in organizations: A critical introduction (4th ed.). Oxford: Oxford University Press.

Hochwarter, W. A., Witt, L. A., Treadway, D. C., \& Ferris, G. R. 2006. The interaction of social skill and organizational support on job performance. Journal of Applied Psychology, 91(2): 482-489.

Holmes, R. M., Jr., Miller, T., Hitt, M. A., \& Salmador, M. P. 2013. The interrelationships among informal institutions, formal institutions, and inward foreign direct investment. Journal of Management, 39(2): 531-566.

House, R. J., Hanges, P. J., Javidan, M., Dorfman, P. W., \& Gupta, V. (Eds.). 2004. Culture, leadership, and organizations: The GLOBE study of 62 societies. Thousand Oaks, CA: Sage.

Imai, L., \& Gelfand, M. J. 2010. The culturally intelligent negotiator: The impact of cultural intelligence (CQ) on negotiation sequences and outcomes. Organizational Behavior and Human Decision Processes, 112(2): 83-98.

Ipe, M. 2003. Knowledge sharing in organizations. A conceptual framework. Human Resource Development Review, 2(4): 337-359.

Jackson, S. E., Chuang, C. H., Harden, E. E., \& Jiang, Y. 2006. Toward developing human resource management systems for knowledge-intensive teamwork. In J. J. Martocchio (Ed.), 
Research in personnel and human resources management (Vol. 25, pp. 27-70). Bingley: Emerald.

Javidan, M., Stahl, G. K., Brodbeck, F., \& Wilderom, C. P. M. 2005. Cross-border transfer of knowledge: Cultural lessons from Project GLOBE. Academy of Management Perspectives, 19(2): 59-76.

Jiang, K., Liu, D., McKay, P. F., Lee, T. W., \& Mitchell, T. R. 2012. When and how is job embeddedness predictive of turnover? A meta-analytic investigation. Journal of Applied Psychology, 97(5): 1077-1096.

Kim, K., Kirkman, B. L., \& Chen, G. 2008. Cultural intelligence and international assignment effectiveness: A conceptual model and preliminary findings. In S. Ang \& L. Van Dyne (Eds.), Handbook of cultural intelligence: Theory, measurement, and applications (pp. 71-90). Armonk, NY: M. E. Sharpe.

Kirkman, B. L., Lowe, K. B., \& Gibson, C. B. 2006. A quarter century of culture's consequences: A review of empirical research incorporating Hofstede's cultural values framework. Journal of International Business Studies, 37(3): 285-320.

Kraimer, M. L., Shaffer, M. A., Harrison, D. A., \& Ren, H. 2012. No place like home? An identity strain perspective on repatriate turnover. Academy of Management Journal, 55(2): 399-420.

Lauring, J., \& Selmer, J. 2012. Knowledge sharing in diverse organisations. Human Resource Management Journal, 22(1): 89-105.

Lee, C. H. 2005. A study of underemployment among selfinitiated expatriates. Journal of World Business, 40(2): 172-187.

Lee, T. W., Burch, T. C., \& Mitchell, T. R. 2014. The story of why we stay: A review of job embeddedness. Annual Review of Organizational Psychology and Organizational Behavior, 1(1): 199-216.

Lee, T. W., Mitchell, T. R., Sablynski, C. J., Burton, J. P., \& Holtom, B. C. 2004. The effects of job embeddedness on organizational citizenship, job performance, volitional absences, and voluntary turnover. Academy of Management Journal, 47(5): 711-722.

Lee, L. Y., \& Sukoco, B. M. 2010. The effects of cultural intelligence on expatriate performance: The moderating effects of international experience. The International Journal of Human Resource Management, 21(7): 963-981.

Li, M., Mobley, W. H., \& Kelly, A. 2012. When do global leaders learn best to develop cultural intelligence? An investigation of the moderating role of experiential learning style. Academy of Management Learning \& Education, 12(1): 32-50.

Lin, C.-W., Kao, M.-C., \& Chang, K.-I. 2010. Is more similar, better? Interacting effect of the cognitive-style congruency and tacitness of knowledge on knowledge transfer in the mentor-protégé dyad. Asian Journal of Social Psychology, 13(4): 286-292.

Liu, Y., \& Phillips, J. S. 2011. Examining the antecedents of knowledge sharing in facilitating team innovativeness from a multilevel perspective. International Journal of Information Management, 31(1): 44-52.

MacNab, B., Brislin, R., \& Worthley, R. 2012. Experiential cultural intelligence development: Context and individual attributes. The International Journal of Human Resource Management, 23(7): 1320-1341.

Malek, M. A., \& Budhwar, P. 2013. Cultural intelligence as a predictor of expatriate adjustment and performance in Malaysia. Journal of World Business, 48(2): 222-231.

Mesmer-Magnus, J. R., \& DeChurch, L. A. 2009. Information sharing and team performance. A meta-analysis. Journal of Applied Psychology, 94(2): 535-546.

Miller, R. B., \& Hollist, C. S. 2007. Attrition bias. In E. N. Salkind (Ed.), Encyclopedia of measurement and statistics (Vol. 1, pp. 57-60). Thousand Oaks, CA: Sage.
Minbaeva, D. B., Mäkelä, K., \& Rabbiosi, L. 2012. Linking HRM and knowledge transfer via individual-level mechanisms. Human Resource Management, 51(3): 387-405.

Mitchell, T. R., Holtom, B. C., Lee, T. W., Sablynski, C. J., \& Erez, M. 2001. Why people stay: Using job embeddedness to predict voluntary turnover. Academy of Management Journal, 44(6): 1102-1121.

Mor, S., Morris, M. W., \& Joh, J. 2013. Identifying and training adaptive cross-cultural management skills. The crucial role of cultural metacognition. Academy of Management Learning \& Education, 12(3): 453-475.

$\mathrm{Ng}$, T. W., \& Feldman, D. C. 2010. The impact of job embeddedness on innovation-related behaviors. Human Resource Management, 49(6): 1067-1087.

$\mathrm{Ng}, \mathrm{T}$. W., \& Feldman, D. C. 2011. Locus of control and organizational embeddedness. Journal of Occupational and Organizational Psychology, 84(1): 173-190.

Nguyen, T.-M., Nham, T. P., Froese, F. J., \& Malik, A. 2019. Motivation and knowledge sharing: A meta-analysis of main and moderating effects. Journal of Knowledge Management, 23(5): 998-1016.

Nisbett, R. E. 2003. The geography of thought. How Asians and Westerners think differently... and why. New York, NY: Free Press.

Nishii, L. H. 2013. The benefits of climate for inclusion for gender-diverse groups. Academy of Management Journal, 56(6): 1754-1774.

North, D. C. 1990. Institutions, institutional change and economic performance. Cambridge: Cambridge University Press.

Oakes, P. J., Turner, J. C., \& Haslam, S. A. 1991. Perceiving people as group members: The role of fit in the salience of social categorizations. British Journal of Social Psychology, 30(2): 125-144.

Oberg, K. 1960. Cultural shock: Adjustment to new cultural environments. Practical Anthropology, 7(4): 177-182.

Oddou, G., \& Mendenhall, M. 1984. Person perception in crosscultural settings: A review of cross-cultural and related cognitive literature. International Journal of Intercultural Relations, 8(1): 77-96

Ott, D. L., \& Michailova, S. 2018. Cultural intelligence: A review and new research avenues. International Journal of Management Reviews, 20(1): 99-119.

Peltokorpi, V. 2006. Knowledge sharing in a cross-cultural context: Nordic expatriates in Japan. Knowledge Management Research \& Practice, 4(2): 138-148.

Peltokorpi, V., Allen, D. G., \& Froese, F. 2015. Organizational embeddedness, turnover intentions, and voluntary turnover: The moderating effects of employee demographic characteristics and value orientations. Journal of Organizational Behavior, 36(2): 292-312.

Peltokorpi, V., \& Froese, F. J. 2014. Expatriate personality and cultural fit: The moderating effect of country context on job satisfaction. International Business Review, 23(1): 293-302.

Peng, M. W., Wang, D. Y., \& Jiang, Y. 2008. An institution-based view of international business strategy: A focus on emerging economies. Journal of International Business Studies, 39(5): 920-936.

Podsakoff, P. M., MacKenzie, S. B., Lee, J. Y., \& Podsakoff, N. P. 2003. Common method biases in behavioral research: $A$ critical review of the literature and recommended remedies. Journal of Applied Psychology, 88(5): 879-903.

Ramesh, A., \& Gelfand, M. J. 2010. Will they stay or will they go? The role of job embeddedness in predicting turnover in individualistic and collectivistic cultures. The Journal of Applied Psychology, 95(5): 807-823.

Redding, G. 2005. The thick description and comparison of societal systems of capitalism. Journal of International Business Studies, 36(2): 123-155. 
Ren, H., Shaffer, M. A., Harrison, D., Fu, C., \& Fodchuk, K. M. 2014. Reactive adjustment or proactive embedding? Multistudy, multiwave evidence for dual pathways to expatriate retention. Personnel Psychology, 67(1): 203-239.

Riege, A. 2005. Three-dozen knowledge-sharing barriers managers must consider. Journal of Knowledge Management, 9(3): 18-35.

Rockstuhl, T., Eisenberger, R., Shore, L. M., Kurtessis, J. N., Ford, M. T., Buffardi, L. C., et al. 2020. Perceived organizational support (POS) across 54 nations: A cross-cultural meta-analysis of POS effects. Journal of International Business Studies. https:// doi.org/10.1057/s41267-020-00311-3.

Sanchez, J. I., Spector, P. E., \& Cooper, C. L. 2000. Adapting to a boundaryless world: A developmental expatriate model. Academy of Management Perspectives, 14(2): 96-106.

Sarti, D. 2018. Organizational tenure and knowledge-sharing behaviours. Journal of Workplace Learning, 30(4): 291-307.

Shaffer, M. A., \& Miller, G. 2008. Cultural intelligence: A key success factor for expatriates. In S. Ang \& L. Van Dyne (Eds.), Handbook of cultural intelligence: Theory, measurement, and applications (pp. 107-125). M. E. Sharpe: Armonk, NY.

Shin, S. J., Morgeson, F. P., \& Campion, M. A. 2007. What you do depends on where you are. Understanding how domestic and expatriate work requirements depend upon the cultural context. Journal of International Business Studies, 38(1): 64-83.

Shore, L. M., Randel, A. E., Chung, B. G., Dean, M. A., Holcombe Ehrhart, K., \& Singh, G. 2011. Inclusion and diversity in work groups: A review and model for future research. Journal of Management, 37(4): 1262-1289.

Smale, A., Bagdadli, S., Cotton, R., Dello Russo, S., Dickmann, M., Dysvik, A., et al. 2019. Proactive career behaviors and subjective career success. The moderating role of national culture. Journal of Organizational Behavior, 40(1): 105-122.

Sonesh, S. C., \& DeNisi, A. S. 2016. The categorization of expatriates and the support offered by host country nationals. Journal of Global Mobility, 4(1): 18-43.

Szulanski, G. 1996. Exploring internal stickiness: Impediments to the transfer of best practice within the firm. Strategic Management Journal, 17(S2): 27-43.

Takeuchi, R., Tesluk, P. E., Yun, S., \& Lepak, D. P. 2005. An integrative view of international experience. Academy of Management Journal, 48(1): 85-100.

Tett, R. P., \& Burnett, D. D. 2003. A personality trait-based interactionist model of job performance. Journal of Applied Psychology, 88(3): 500-517.

Tett, R. P., \& Guterman, H. A. 2000. Situation trait relevance, trait expression, and cross-situational consistency: Testing a principle of trait activation. Journal of Research in Personality, 34(4): 397-423.

Tett, R. P., Simonet, D. V., \& Brown, C. 2013. Trait activation theory: Applications, developments, and implications for person-workplace fit. In N. Christiansen \& R. P. Tett (Eds.), Handbook of personality at work (pp. 71-100). New York, NY: Routledge.

Tharenou, P., \& Caulfield, N. 2010. Will I stay or will I go? Explaining repatriation by self-initiated expatriates. Academy of Management Journal, 53(5): 1009-1028.

Thomas, D. C. 2006. Domain and development of cultural intelligence. Group and Organization Management, 31(1): 78-99.

Thomas, D. C., Elron, E., Stahl, G., Ekelund, B. Z., Ravlin, E. C., Cerdin, J.-L., et al. 2008. Cultural intelligence: Domain and assessment. International Journal of Cross Cultural Management, 8(2): 123-143.

Thomas, D. C., Liao, Y., Aycan, Z., Cerdin, J.-L., Pekerti, A. A., Ravlin, E. C., et al. 2015. Cultural intelligence: A theory-based, short form measure. Journal of International Business Studies, 46(9): 1099-1118.
Toh, S. M., \& DeNisi, A. S. 2007. Host country nationals as socializing agents: A social identity approach. Journal of Organizational Behavior, 28(3): 281-301.

United Nations. 2013. International migration policies 2013: Government views and priorities. New York, NY: United Nations.

United Nations. 2013b. International migration policies (wall chart). Retrieved November 20, 2016, from https://www.un. org/en/development/desa/population/publications/pdf/ policy/InternationalMigrationPolicies2013/ InternationalMigrationPolicies2013_WallChart.pdf.

Van Vianen, A. E., De Pater, I. E., Kristof-Brown, A. L., \& Johnson, E. C. 2004. Fitting in: Surface-and deep-level cultural differences and expatriates' adjustment. Academy of Management Journal, 47(5): 697-709.

Varma, A., Toh, S. M., \& Budhwar, P. 2006. A new perspective on the female expatriate experience: The role of host country national categorization. Journal of World Business, 41(2): 112-120.

Wang, S., \& Noe, R. A. 2010. Knowledge sharing: A review and directions for future research. Human Resource Management Review, 20(2): 115-131.

Wang, S., Tong, T. W., Chen, G., \& Kim, H. 2009. Expatriate utilization and foreign direct investment performance. The mediating role of knowledge transfer. Journal of Management, 35(5): 1181-1206.

Ward, C., Fischer, R., Zaid Lam, F. S., \& Hall, L. 2008. The convergent, discriminant, and incremental validity of scores on a self-report measure of cultural intelligence. Educational and Psychological Measurement, 69(1): 85-105.

Yang, H., van Rijn, M. B., \& Sanders, K. 2018. Perceived organizational support and knowledge sharing. Employees' self-construal matters. The International Journal of Human Resource Management. https://doi.org/10.1080/09585192. 2018.1443956.

Zhang, Y. 2013. Expatriate development for cross-cultural adjustment. Effects of cultural distance and cultural intelligence. Human Resource Development Review, 12(2): 177-199.

Zhang, M., Fried, D. D., \& Griffeth, R. W. 2012. A review of job embeddedness. Conceptual, measurement issues, and directions for future research. Human Resource Management Review, 22(3): 220-231.

\section{ABOUT THE AUTHORS}

Sebastian Stoermer is an Assistant Professor at TU Dresden, Germany. He obtained his doctorate in Management from the University of Goettingen, Germany. His research interests lie in the fields of Human Resource Management and Organizational Behavior.

Samuel Davies is Lecturer in Human Resource Management and Organizational Behavior at the University of Liverpool Management School, UK. He holds a doctorate in Management from the University of Goettingen, Germany. His research often intersects across International (Human Resource) Management and Organizational Behavior. 
Fabian Jintae Froese is Professor of Human Resource Management and Asian Business at the University of Goettingen, and Joint Appointment Professor of International Business at the School of Business, Yonsei University. He received a doctorate in international management from the University of St. Gallen and another doctorate in sociology from Waseda University. His research interests lie in international HRM.
Open Access This article is licensed under a Creative Commons Attribution 4.0 International License, which permits use, sharing, adaptation, distribution and reproduction in any medium or format, as long as you give appropriate credit to the original author(s) and the source, provide a link to the Creative Commons licence, and indicate if changes were made. The images or other third party material in this article are included in the article's Creative Commons licence, unless indicated otherwise in a credit line to the material. If material is not included in the article's Creative Commons licence and your intended use is not permitted by statutory regulation or exceeds the permitted use, you will need to obtain permission directly from the copyright holder. To view a copy of this licence, visit http://creativecommons.org/licenses/by/4.0/.

Publisher's Note Springer Nature remains neutral with regard to jurisdictional claims in published maps and institutional affiliations.

Accepted by Mary Teagarden, Area Editor, 9 May 2020. This article has been with the authors for two revisions. 